\title{
Ulcerated Lesion in Buccal Mucosa in a Patient with Paracoccidioidomycosis-Case Report
}

\author{
Giovanna Lima Vaz¹, Lívia Cristina de Melo Pino ${ }^{1}$, Aline Gabriela Santos Costa ${ }^{1}$, \\ Ibrahim Yahia El Somailli', João Roberto Resende Fernandes', \\ Elayne Christina Meireles Martins' ${ }^{1}$, Daniel Cohen Goldemberg', \\ Aline Hellen da Silva Camacho ${ }^{2}$, Rhanna Neves Cirqueira ${ }^{3}$, Daniel Almeida da Costa ${ }^{1}$ \\ ${ }^{1}$ College of Medicine of Valença-FAA/Cesva, Valença, Brazil \\ ${ }^{2}$ National Cancer Institute-INCA, Rio de Janeiro, Brazil \\ ${ }^{3}$ Centro Universitário de Belo Horizonte-UNIBH, Belo Horizonte, Brazil \\ Email: professordanielfmv@gmail.com
}

How to cite this paper: Vaz, G.L., de Melo Pino, L.C., Costa, A.G.S., El Somailli, I.Y., Fernandes, J.R.R., Martins, E.C.M., Goldemberg, D.C., da Silva Camacho, A.H., Cirqueira, R.N. and da Costa, D.A. (2017) Ulcerated Lesion in Buccal Mucosa in a Patient with Paracoccidioidomycosis-Case Report. Journal of Biosciences and Medicines, 5, 44-50.

https://doi.org/10.4236/jbm.2017.510005

Received: August 11, 2017

Accepted: October 23, 2017

Published: October 26, 2017

Copyright $\odot 2017$ by authors and Scientific Research Publishing Inc. This work is licensed under the Creative Commons Attribution International License (CC BY 4.0).

http://creativecommons.org/licenses/by/4.0/
(c) (i) Open Access

\begin{abstract}
Paracoccidioidomycosis is the most prevalent systemic mycosis in Latin America. It is a fungal infection caused by the dimorphic fungus Paracoccidioides brasiliensis. This microorganism can penetrate the human body through direct contact and can cause intense lymphadenopathy, ulcerated lesions in the oral cavity and in the skin among other alterations. In this study, we report a case of paracoccidioidomycosis with unusual clinical presentation, as it manifested in the female sex and although it did not present any relevant complaints of respiratory focus, it presented a single ulcerated lesion in the buccal mucosa. A biopsy of the lesion and a mycological examination revealed Paracoccidioides brasiliensis infection.
\end{abstract}

\section{Keywords}

Paracoccidioidomycosis, Paracoccidioides brasiliensis, Endemic Mycosis

\section{Introduction}

PCM has a geographical distribution restricted to Latin American countries, with a higher incidence in Brazil, Venezuela and Colombia, and is more frequently diagnosed in the State of São Paulo [1] [2] [3].

Its actual incidence cannot be calculated because PCM is not a compulsory notification disease, but in the endemic areas, it is believed that 3 cases per 100,000 inhabitants occur [4] [5].

The PCM infection does not privilege ethnicity or gender; Since the PCM dis- 
ease mainly affects male rural workers, in constant contact with the soil and vegetation, in the productive phase of their professional life, which implies an important economic repercussion for the patient and his dependents [6].

In addition, abusive alcohol consumption and smoking habits are constantly observed in this population [7] [8]. Pre-existing risk factors or conditions are considered and play an important role in the transformation from infection to manifest disease, since they decrease host defense mechanisms with implications for the quality of granuloma formation [9].

Contamination of the host occurs most frequently through the inhalation of conidia and mycelial fragments, which reach the terminal bronchioles and pulmonary alveoli, where they become yeast cells, producing the infection that can spread to other tissues via the lymphatic and hematogenous routes. The fungus can also be installed on the skin and mucous membranes by traumatic inoculation [3] [10].

Subclinical infection occurs silently. Even in silence, this infection can subsequently lead to clinically manifest disease. The existence of reports of disease in patients diagnosed outside recognized areas of endemicity, in good health after leaving their countries of endemicity, indicates that the dormant fungus is able to revitalize [11] [12].

Mycosis spreads and becomes progressive, when the host cannot contain the fungal growth giving rise to several signs and symptoms [13].

The clinical manifestations are varied and therefore allowed the characterization of two different clinical presentations, namely the acute/subacute or juvenile form and the adult "progressive" or chronic form. The most aggressive manifestations are recorded for the acute/subacute forms, whereas in patients with chronic form the progression is slow and accompanied by residual scars. Patients with any progressive form of disease usually complain of fever and constitutional symptoms such as malaise, adynamia, asthenia, weight loss and anorexia [14] [15] [16].

The acute/subacute (juvenile) form occurs in about $10 \%$ of cases, it is considered pathology of the organs of the reticuloendothelial system. These become hypertrophic, generating, lymph node enlargement and hepatosplenomegaly. Usually, there is no clinically apparent pulmonary involvement, but imaging studies have revealed pulmonary abnormalities in all cases [17] [18].

As already suggested by the name, it is a disease of young people and is diagnosed mainly in undernourished children and adults less than 30 years of age [19].

Cutaneous lesions are observed regularly in the juvenile form (43\%) and are located on the face, perioral, neck and trunk regions preferably. Such lesions are ulcerated, nodular or vegetative; Skin lesions are papular or acneiform in widely disseminated cases [13] [19] [20].

Other organs that can also be affected, with a lower frequency are stomach, duodenum and intestines. Bone involvement is an important component of juvenile form and is observed in $45 \%$ of patients, with predominant lesions in the upper limbs and ribs [13] [19] [20] [21]. 
In patients coinfected with HIV who present the acute/subacute form, a rapid progression of the disease occurs accompanied by fever, lymphatic involvement, mucosal lesions and hepatosplenomegaly [7] [22] [23].

The adult chronic form is the most common presentation observed in approximately $90 \%$ of cases. The prevalence is patients from 35 to 60 years of age, with predominance of male patients. In general, the disease appears to represent endogenous reactivation occurring years after initial contact with the fungus, as shown by diagnosed cases, United States, Europe, and Asia in patients who left endemicity countries many years earlier [11] [12] [24].

Signs and symptoms take months to years to become apparent in this form of disease; there is generally significant lung damage associated with extrapulmonary lesions. Image and scan studies have revealed that mycosis is a multiorgan disease, regardless of the presence or absence of symptoms related to a particular organ [15] [16] [24].

The treatment of the patient with Paracoccidioidomycosis depends on the severity of the disease and must include, besides the use of antifungal drugs, the use of measures that improve the patient's general conditions and post-therapeutic follow-up. Intravenous Amphotericin B is usually indicated for the most severe cases of the disease. Sulfonamide derivatives have been used since the 1940s to treat infection, and such drugs are still used today in many situations [25].

\section{Objective}

The objective of this work is to present a clinical case, together with a literature review, which reports the occurrence of a lesion in the buccal cavity of a patient of 53 years of age caused by the fungus Paracoccidioides brasiliensis and the management of this patient in the doctor's office.

\section{Methodology}

Case report and bibliographic review.

\section{Presentation of the Clinical Case}

A 53-year-old female patient, a long-time smoker, from the rural region of Valença-RJ, Brazil. She presented to the Dermatology outpatient clinic of the Medical School at Luiz GioseffiJannuzzi, Valença, RJ School Hospital. It reported the occurrence of mildly painful whitish oral lesions about two years ago, at which time Fluconazole $150 \mathrm{mg}$ (triazole antifungal) was used and observed improvement, however, the lesions returned after a time and the patient used the same medication. In this way, the lesions began to become thicker and more painful, which made it look for the Service of Dermatology, in which the histopathological examination was carried out, aiming at confirming the diagnosis.

In time, she reports dry cough and moderate dyspnoea to great efforts about 1 $1 / 2$ years ago. She's been hypertensive for 10 years.

Physical examination showed: stained, hydrated, acyanotic, anicteric, with 
good capillary perfusion, afebrile, normal heart rate, eupneic, and normotensive. Abdomen painless to deep palpation and absence of abdominal masses, area of ulcer-granulomatous lesion was observed in the buccal mucosa, without gingival inflammation (Figure 1).

The silver methenamine staining of Grocott-Gomori (or GMS) is a technique for visualization of fungi in tissues fixed in formalin and included in paraffin. It is a silver impregnation (methenamine-silver solution) that highlights the cell wall of the fungi in colors ranging from yellow-gold to black, depending on the time of impregnation. The surrounding tissue does not blush or appear pale, and may be shrunk for better localization of the parasites in relation to the cells, as shown in Figure 2, where Paracoccidioides brasiliensis fungal structures have been revealed (Figure 2).

Histopathological examination revealed a chronic granulomatous inflammatory process, ulcerated, with round and occasionally crescent structures with a double refractory wall compatible with paracoccidioidomycosis.

After the definitive diagnosis the patient was treated with Itraconazol $100 \mathrm{mg}$ for 12 months, to obtain an adequate systemic treatment. Laboratory tests, abdominal

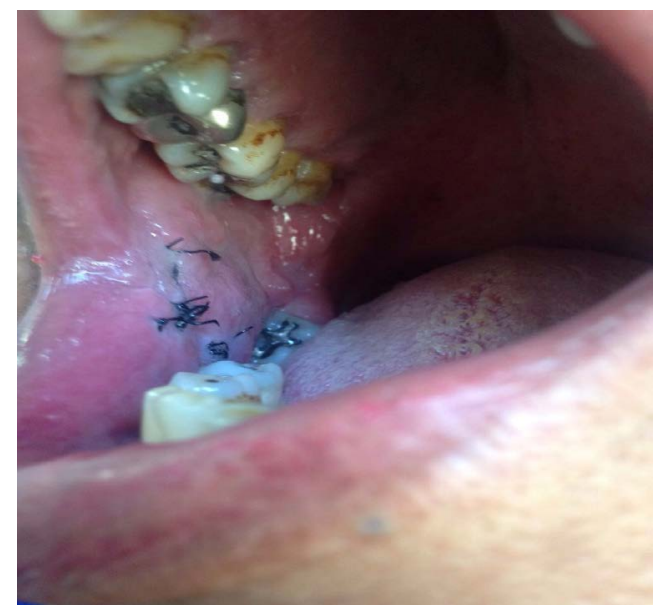

Figure 1. Ulcerated lesions on jugal mucosa.

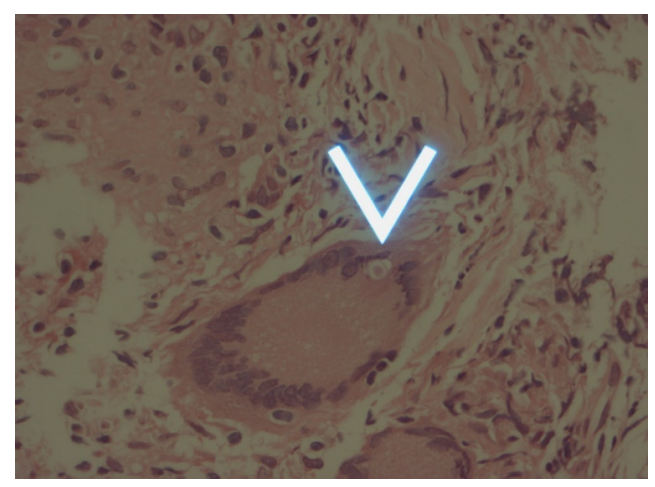

Figure 2. Histopathology shows the presence of fungal structures related to Paracoccidioides brasiliensis. 
ultrasonography, and chest tomography were requested and sent to the dental surgeon to treat the patient's dent/periodontal conditions.

\section{Discussion}

Although PCM is a well-known disease, there are reports of cases in which the diagnosis is difficult.

This case is an attempt to evaluate a rigorous assessment of general health conditions during the clinical examination, which is sometimes neglected by a significant number of professionals [5].

The clinical presentation presented by the patient was not suggestive of the infection caused by the $P$. brasiliensis fungus, which makes it difficult to diagnose it. In addition, the age group and because it is a question of being female had relevance to make difficult the establishment of the clinical diagnosis. Clinical and epidemiological data, particularly in the presence of chronic lung disease and/or chronic tegumentary lesions in patients with a history of agricultural work, even if in the distant past, should alert the clinician to the possibility of PCM. The possibility of involvement of the lung, bone lesions and other organs makes it prudent to refer the patient to the physician for joint action in the case. According to Boraks, complete healing is not always possible, but periods of remission of symptoms can last for years [26].

\section{Conclusion}

Early diagnosis of PCM is important since the therapy is able to reduce the morbidity and mortality of this disease. Therefore, even in regions of low incidence of the disease, this should be remembered. The purpose of the above-mentioned case report was to highlight the importance of anamnesis, the diagnosis and the appropriate treatment of this serious pathology that can be fatal.

In addition, multidisciplinary management allows the adoption of the best support measures to address the systemic changes associated with diseases, such as malnutrition, associated comorbidities, as well as dental treatment, it should be emphasized that follow-up for extended periods is mandatory.

\section{References}

[1] Barrozo, L.V., et al. (2009) Climate and Acute/Subacute Paracoccidioidomycosis in a Hyper-Endemic Area in Brazil. International Journal of Epidemiology, 38, 1642-1649. https://doi.org/10.1093/ije/dyp207

[2] Silva, M.R. and Saraiva, L.E.S. (2008) Paracoccidioidomycosis. Dermatologic Clinics, 26, 257-269. https://doi.org/10.1016/j.det.2007.11.005

[3] Calle, D., et al. (2001) Paracoccidioidomycosis in Colombia: An Ecological Study. Epidemiology and Infection, 126, 309-315. https://doi.org/10.1017/S0950268801005052

[4] San Blas, G., Vega, G.N. and Iturriaga, T. (2002) Paracoccidioides brasiliensis and Paracoccidioidomycosis: Molecular Approaches to Morphogenesis, Diagnosis, Epidemiology, Taxonomy and Genetics. Medical Mycology, 40, 225-242. https://doi.org/10.1080/mmy.40.3.225.242 
[5] Restrepo, A., Mcewen, J.G. and Castaneda, E. (2001) The Habitat of Paracoccidioidesbrasiliensis: How Far from Solving the Riddle? Medical Mycology, 39, 233-241. https://doi.org/10.1080/mmy.39.3.233.241

[6] Marques, S.A., et al. (1983) Epidemiological Aspects of Paracoccidioidomycosis in the Endemic Area of Botucatu (Sao Paulo-Brazil). Revistado Instituto de Medicina Tropica, 25, 87-92.

[7] Martinez, R. and Moya, M.J. (1992) The Relationship between Paracoccidioidomycosis and Alcoholism. Revista de Saúde Pública, 26, 12-16. https://doi.org/10.1590/S0034-89101992000100003

[8] Marques, S.A., et al. (2007) Paracoccidioidomicose: freqüência, morfologia e patogênese de lesões tegumentares. Anais Brasileiros de Dermatologia, 82, 411-417. https://doi.org/10.1590/S0365-05962007000500003

[9] Camargo, Z.P., et al. (2000) Current Knowledge on Pathogenesis and Immunodiagnosis of Paracoccidioidomycosis. Revistaiberoamericana de micología, 17, 41-48.

[10] Franco, M. (1987) Host-Parasite Relationships in Paracoccidioidomycosis. Journal of Medical and Veterinary Mycology, 25, 5-18. https://doi.org/10.1080/02681218780000021

[11] Manns, B.J., et al. (2008) Paracoccidioidomycosis: Case Report and Review. Clinical Infectious Diseases, 23, 1026-1032.

[12] Walker, S.L., Pembroke, A.C., Lucas, S.B., et al. (2008) Paracoccidioidomycosis Presenting in the UK. British Journal of Dermatology, 158, 624-626. https://doi.org/10.1111/j.1365-2133.2007.08346.x

[13] Blotta, M.H., et al. (1999) Endemic Regions of Paracoccidioidomycosis in Brazil: A Clinical and Epidemiologic Study of 584 Cases in the Southeast Region. The American Journal of Tropical Medicine and Hygiene, 61, 390-394. https://doi.org/10.4269/ajtmh.1999.61.390

[14] Campos, M.V.S., et al. (2008) Paracoccidioidomycosis at Brasilia's University Hospital. Revista da Sociedade Brasileira de Medicina Tropical, 41, 169-172. https://doi.org/10.1590/S0037-86822008000200007

[15] Nucci, M., Colombo, A.L. and Queiroz-Telles, F. (2009) Paracoccidioidomycosis. Current Fungal Infection Reports, 3, 15-20. https://doi.org/10.1007/s12281-009-0003-0

[16] Restrepo, A., et al. (2008) Pulmonary Paracoccidioidomycosis. In: Seminars in Respiratory and Critical Care Medicine, Thieme Medical Publishers, 182-197. https://doi.org/10.1055/s-2008-1063857

[17] Marchiori, E., et al. (2011) Paracoccidioidomycosis: High-Resolution Computed Tomography-Pathologic Correlation. European Journal of Radiology, 77, 80-84.

[18] Yamaga, L.Y.I., et al. (2003) The Role of Gallium-67 Scan in Defining the Extent of Disease in an Endemic Deep Mycosis, Paracoccidioidomycosis: A Predominantly Multifocal Disease. European Journal of Nuclear Medicine and Molecular Imaging, 30, 888-894. https://doi.org/10.1007/s00259-003-1172-7

[19] Pereira, R.M., et al. (2004) Paracoccidioidomycosis in Children: Clinical Presentation, Follow-Up and Outcome. Revista do Instituto de Medicina Tropical de São Paulo, 46, 127-131. https://doi.org/10.1590/S0036-46652004000300002

[20] Londero, A.T. and Ramos, C.D. (1990) Paracoccidioidomycosis. Clinical and Mycological Study of 260 Cases Observed in the Interior of the State of Rio Grande do Sul. Jornal Brasileiro de Pneumologia, 16, 129-132.

[21] Lacaz, C.S., et al. (2002) Treaty of Medical Mycology-Lacaz. Editora Sarvier, São 
Paulo.

[22] Morejón, K.M., Machado, L., Artioli, A., et al. (2009) Paracoccidioidomycosis in Patients Infected with and Not Infected with Human Immunodeficiency Virus: A Case-Control Study. The American Journal of Tropical Medicine and Hygiene, 80, 359-366.

[23] Paniago, A.M.M., et al. (2005) Paracoccidioidomycosis in Patients with Human Immunodeficiency Virus: Review of 12 Cases Observed in an Endemic Region in Brazil. Journal of Infection, 51, 248-252.

[24] Restrepo, A., Tobón, A.M. and Agudelo, C.A. (2008) Paracoccidioidomycosis. In: Diagnosis and Treatment of Human Mycoses, Humana Press, 331-342. https://doi.org/10.1007/978-1-59745-325-7 18

[25] Neville, B.W., et al. (1998) Patologia Oral e Maxilofacial. Guanabara Koogan, Rio de Janeiro, 711 .

[26] Boraks, S. (1996) InfectiousDiseases. In: Boraks, Silvio. Diagnóstico bucal, Artes Médicas, São Paulo, 150-153. 